\title{
Colibacilosis en gallinas reproductoras pesadas en reproducción
}

\author{
Colibacillosis in reproducing heavy reproductive hens \\ Colibacilose na reprodução de galinhas reprodutoras pesadas \\ Díaz Rojas María del Pilar ${ }^{1}$ y González Paya Gustavo Gratiniano² \\ ${ }^{1}$ Medica Veterinaria y Zootecnista Universidad de los Llanos y \\ ${ }^{2} \mathrm{MV}$, Esp. Docente Universidad de los Llanos \\ maria.diaz@unillanos.edu.co
}

Recibido 18 de julio 2019, Aceptado octubre 30 de 2019

\section{RESUMEN}

La colibacilosis en gallinas reproductoras se da por la bacteria Gram negativa, enterobacteria Escherichia coli patogénica aviar (APEC), ella presenta un porcentaje alto de polimorfismos y plasticidad en su genes, las investigaciones reportan hallazgos macroscópicos comunes: salpingitis, peritonitis y poliserositis, que conlleva a la muerte del ave, se definen tres rutas de contaminación, de forma ascendente por la cloaca del ave, ingreso por vía respiratoria o por translocación bacteriana desde el intestino, el diagnóstico de la colibacilosis, se realiza a partir del historial del galpón, realizando las necropsias y tomando muestra a partir de hisopos o tejido de órganos como oviducto, pulmón, corazón u órganos afectados se llevan a medios como McConkey, eosin-methylene blue o agar drigalki para su aislamiento, pruebas específicas de la Esceherichia coli se conoce métodos basados en fenotipos como serotipo de $\mathrm{O} / \mathrm{H}$ inmunológico,tipificación de bacteriófago, electroforesis con enzimas multilocus, MALDI-TOF y métodos basados en genotipos como polimorfismo de longitud de restricción (RFLP), ensayo de suspensión basado en liminex, polimorfismo de longitud de fragmentos amplificados (AFLP), mapeo óptico, las vacunas para esta bacteria no se han desarrollado a la perfección ya que presenta respuesta inmune ante sus homólogos, pero nada de resistencia a desafíos con heterólogos, sigue en investigación realizar vacunas que puedan presentar respuesta inmune a varios serotipos de la bacteria, 
por ahora la forma eficaz de controlar la bacteria a partir de protocolos de bioseguridad y prevención para la mantener la sanidad del animal.

Palabras clave: Escherichia spp, avicultura, diagnóstico, patogénesis, prevención.

\begin{abstract}
The colibacilosis in breeding hens is given by Gram negative bacteria, enterobacteria pathogenic avian pathogenic Escherichia coli (APEC), it has a high percentage of polymorphisms and plasticity in its genes, research reports common macroscopic findings: salpingitis, peritonitis and polyserositis, which entails At the death of the bird, three routes of contamination are defined, ascending through the cloaca of the bird, entry by respiratory or bacterial translocation from the intestine, the diagnosis of colibacillosis, is made from the history of the house, making necropsies and taking samples from swabs or tissue from organs such as oviduct, lung, heart or affected organs are carried to means such as McConkey, eosinmethylene blue or agar drigalki for their isolation, specific tests of the Esceherichia coli are known based methods in phenotypes such as serotyping $\mathrm{O} / \mathrm{H}$ immunological, bacteriophage typing, electro foresis with multilocus enzymes, MALDI-TOF and methods based on genotypes such as restriction length polymorphism (RFLP), liminex-based suspension assay, amplified fragment length polymorphism (AFLP), optical mapping, vaccines for this bacterium are not have developed to perfection since it presents an immune response to its counterparts, but no resistance to challenges with heterologous, research continues to carry out vaccines that may present an immune response to several serotypes of the bacteria, for now the effective way to control the bacteria biosafety and prevention protocols to maintain the health of the animal.
\end{abstract}

Keywords: Escherichia spp, poultry, diagnosis, pathogenesis, prevention. 


\section{RESUMO}

Colibacilose em galinhas reprodutoras para as bactérias Gram negativas é dado, enterobactérias Escherichia coli aviária de alta patogenicidade (APEC), que tem uma elevada percentagem de polimorfismos e plasticidade em seus genes, relatório de pesquisa achados macroscópicos comuns: salpingite, peritonite e poliserositis, envolvendo a morte do pássaro, três vias de contaminação ascender ao céu definido pela abertura do pássaro, vias aéreas renda ou translocação bacteriana do intestino, diagnóstico de colibacilose, são feitos a partir da história da casa, carregando necropsias e tendo amostra de esfregaço ou de tecido de órgãos como oviduto, pulmão, coração ou órgãos afectados ter meios como McConkey, drigalki azul ou ágar-eosina de metileno, durante o isolamento, os testes específicos Esceherichia coli métodos baseados é conhecida em fenótipos como o sorotipo $\mathrm{O} / \mathrm{H}$ imunológico, tipagem bacteriofágica, eletroforese resis com genótipos enzima multilocus, baseados em MALDI-TOF como polimorfismo de comprimento de restrio (RFLP) fragmento ensaio baseado suspensão polimorfismo de comprimento liminex amplificado (AFLP), mapeamento óptico, vacinas para estes métodos não são bactérias têm desenvolvido à perfeição como ele apresenta resposta imune aos seus homólogos, mas nenhuma resistência aos desafios com heterólogas ainda vacinas make investigação que possam surgir respostas imunes a vários sorotipos da bactéria, agora a maneira eficaz de controlar as bactérias protocolos de biossegurança e prevenção para manter a saúde do animal.

Palavras-chave: Escherichia spp, aves, diagnóstico, patogênese, prevenção.

\section{INTRODUCCIÓN}

La industria avícola, la podemos dividir en dos tipos de producción: la de carne y huevo, esta clasificación divide la industria en dos mercados distintos, y da origen a distintos tipos de organizaciones, cuyo diseño y estructura de modelo de negocio también son diferentes. 
En las gallinas reproductoras se maneja un porcentaje del material genético para la producción de pollo de engorde, en Colombia se maneja dos líneas de reproductoras en las que se encuentran las líneas Cobb y Ross, cada una con características genotípicas para el rendimiento y conversión del alimento en carne en canal.

La avicultura se rige por procesos de bioseguridad estrictos para tener mayor control de la entrada de patógenos a las granjas para no causar enfermedad en las aves, pero hay patógenos que son habitantes normales del ave que durante un desequilibrio en la salud del ave puede producir enfermedad, en el caso de Echerichia coli bacteria Gram negativa, hospedero natural en el ave, en condiciones de estrés produce enfermedad causando gran mortalidad y bajos índices de producción.

La Escherichia coli puede causar daño en las reproductoras al iniciar su etapa de producción, las principales lesiones son: salpingitis, peritonitis, salpingoperitonitis, lo que lleva, a una disminución en la producción de huevo fértil, mayor contaminación en la incubadora, aumento en el tiempo de la ventana de nacimiento, aumentando la muerte embrionaria y reclamos a clientes por muerte temprana de los pollitos de engorde (Barnes y Gross, 1997).

En el sector avícola las enfermedades bacterianas como la Escherichia coli, son el desafío que se enfrentan los veterinarios, por los altos costos de inversión que se realizan y las pérdidas que representan, por eso se implementan protocolos de bioseguridad y normas sanitarias que deben cumplir los trabajadores en la empresa.

Los diferentes avances en la tecnología, hacen la diferencia entre las aves de corral comerciales a los que son criadas en fincas, como base de la sustentación de pequeños productores o empresas familiares, por ende es necesario realizar un revisión teórica del desarrollo causas y métodos de prevención que se deben tener en cuenta con la Escherichia coli y así entender las consecuencias de la enfermedad. 


\section{IDENTIFICACIÓN Y CARACTERIZACIÓN MICROBIOLOGÍA DE LA BACTERIA}

Theodor Escherichia fue pediatra y microbiólogo, reportó el primer aislamiento y caracterización de la bacteria, dándole el nombre de Bacterium coli comune, en su primera publicación (Croxen et al., 2013). El organismo fue descrito después con diferentes sinónimos e interacciones y se le dio el nombre de Escherichia coli, microrganismo que se pertenece al filum Proteobacteria, clase Gammaproteobacteria, orden Enterobacteriales y familia Enterobacteriaceae (Collingwood, 2016). Está bacteria se ha convertido en uno de los organismos modelo para investigaciones, en los cuales se utilizan cepas de laboratorio y estudios comparativos y analíticos (Breland et al., 2017).

Hasta la fecha, más de 3600 genomas de Escherichia coli, se han secuenciado en parte o en su totalidad, revelando siete grupos filogenéticos A, B1, B2, C, D, E, y Fcon los subtipos no clasificados en un octavo grupo (Clermont et al., 2013).

E coli es una bacteria Gram-negativa, oxidasa-negativa, en forma de barra, puede crecer tanto aeróbicamente como anaeróbicamente, preferiblemente a $37^{\circ} \mathrm{C}$, y puede ser inmóvil o móvil, con flagelos peritrichosos. E. coli es aislada a partir de muestras fecales, mediante la siembra en medios selectivos (Salton y Shin, 1996). Mide entre 1 y $3 \mu$ (Figura 1) y algunos factores de virulencia, tiene una capacidad móvil a través de flagelos (antígeno H) que son órganos filiformes que pueden medir varias micras, así mismo también tiene fimbrias (antígeno F) que son órganos pequeños, que a diferencia de los flagelos no poseen movilidad, pero por ser de naturaleza proteica (pilina) tienen propiedades antigénicas y hemoaglutinantes también median la ligadura de bacterias a las células a través de las adhesinas bacterianas, estas pueden medir entre 4 y $7 \mathrm{~nm}$ de diámetro y $2 \mu$ de largo (Vazques, 2011).

El pili se refiere a los pelos ligeramente largos que se utilizan en la conjugación bacteriana para intercambiar material genético desde la célula donadora hasta la receptora y a veces en el desplazamiento, posee pared celular (antígeno O) que está conformada por lipopolisacáridos (LPS) antigénicos y con capacidad de 
excretar endotoxinas, así mismo posee capsula (antígeno K) que le otorga algunas capacidades para evadir la fagocitosis y la acción de inmunidad primaria (Dho y Morris, 1999; Collingwood, 2016).

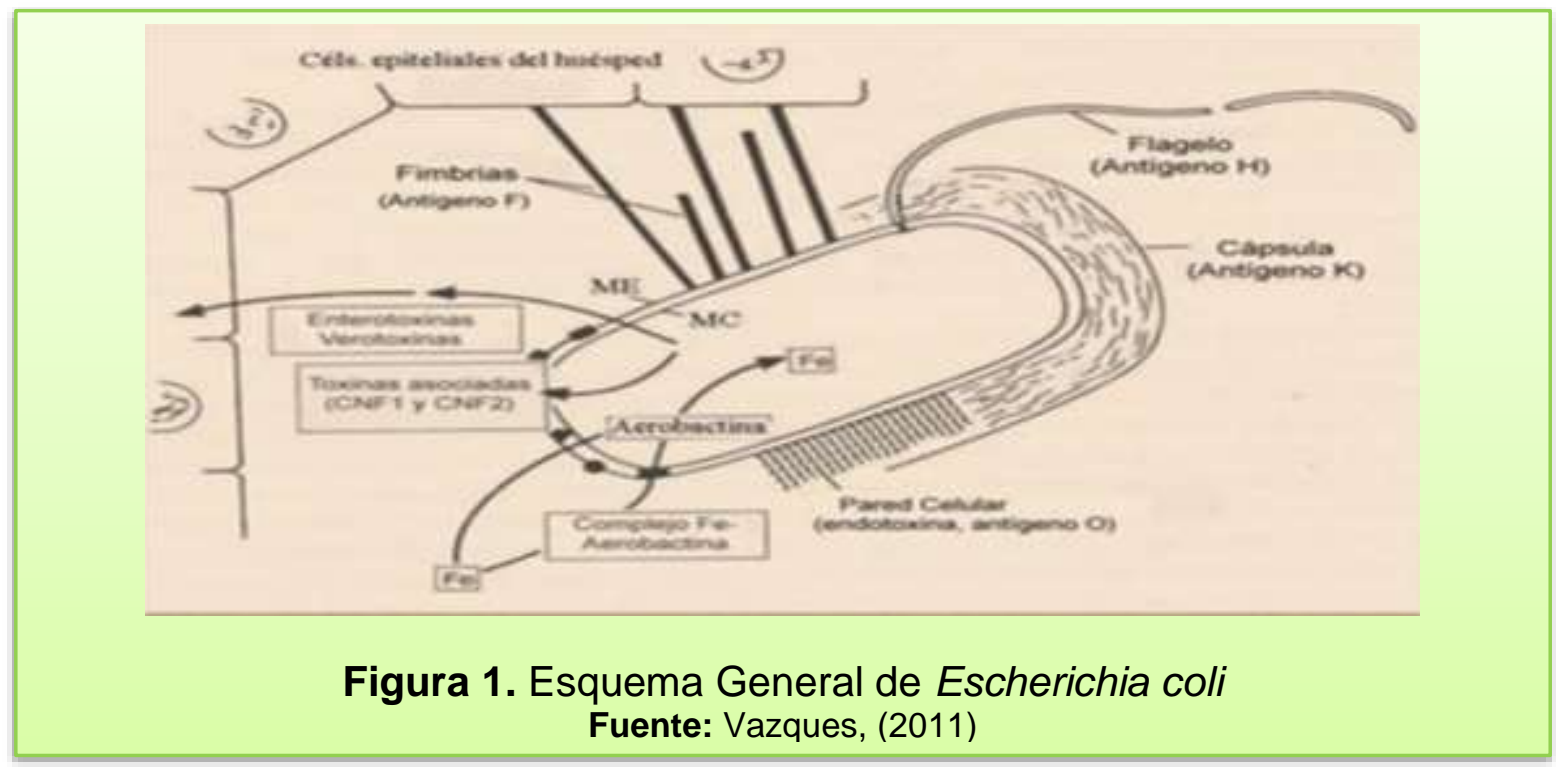

La genómica comparada ha demostrado, que los genomas de E. coli se dividen entre un conjunto de genes compartido y conservado, denominado genoma central, y un conjunto de genes flexible llamado pangenoma (Kaas et al., 2012). Por lo tanto, la patogenicidad de $E$. coli está garantizada por el conjunto de genes flexibles, a través de la ganancia y pérdida de material genético, en varios puntos del genoma (Croxen et al., 2013). E. coli fue la primera bacteria para la cual se introdujeron las técnicas genéticas poblacionales, los resultados de la electroforesis de enzimas multilocus (MLEE) indicaron que ciertas combinaciones de alelos ocurrieron múltiples veces, lo que se interpretó como una estructura de población clonal con recombinación (Reid et al.,2000).

Wirth et al., (2006) identificaron siete genes de mantenimiento distribuidos a lo largo del cromosoma de E. coli, a partir de 462 accesiones de diverso origen, aisladas en Europa, África, América del Norte y la Cuenca del Pacífico muestras tomadas de humanos y 41 especies de mamíferos, aves y reptiles domesticados, cautivos y salvajes, además encontraron que el 8 a $20 \%$ de los nucleótidos eran polimórficos, dentro de cada uno de los siete fragmentos de genes (Figura 2B), para un total de 
630 polimorfismos de un solo nucleótido, sobre los 3423 pares de bases (pb) secuenciados de cada cepa, por lo tanto, E. coli es más diversa de lo que se preveía. Los diferentes genes aislados, su nivel de polimorfismo para cada gen indicado en el histograma (Figura 2), donde las barras negras representan el polimorfismo de los nucleótidos y las barras grises el polimorfismo de los ácidos nucleicos, cada símbolo del gen es seguido por la longitud del gen secuenciado (Wirth et al., 2006).

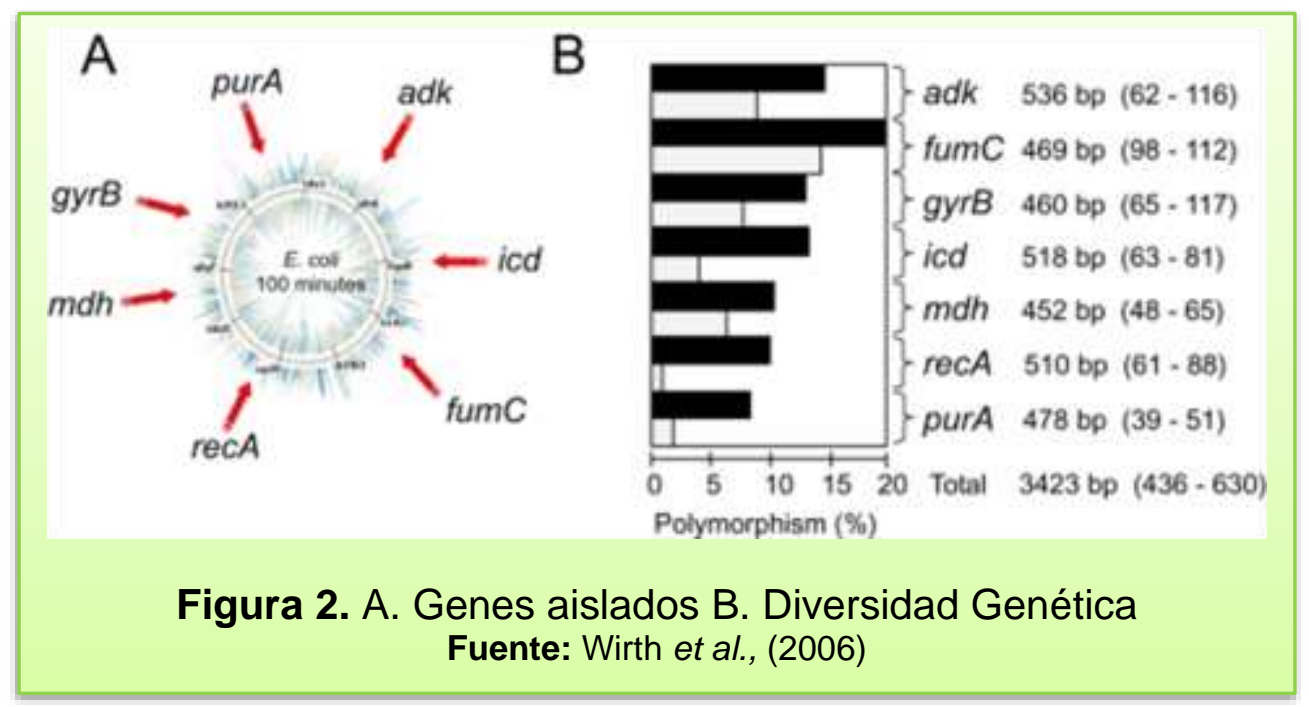

La mayoría de veces $E$. coli coloniza el tracto gastrointestinal (Gl) de los humanos y otros mamíferos son parte de la flora normal del organismo, sin embargo, la adquisición de elementos genéticos, principalmente a través de la transferencia horizontal de genes da lugar a $E$. coli patógenas con distintas estrategias de virulencia (Breland et al., 2017).

Los patotipos de $E$. coli gastrointestinales 0 diarreicos incluyen adherentes difusamente (DAEC), enteroagregativos (EAEC), enterohemorrágicos (EHEC), enteroinvasivos (EIEC), enteropatógenos (EPEC) y enterotoxigénicos (ETEC), han surgido patotipos de E. coli patógenos extraintestinales (ExPEC), e incluyen E. coli patógena aviar (APEC), meningitis neonatal causante $o$ E. coli asociada a meningitis (NMEC/MAEC) y E. coli uropatógena (UPEC), las constantes mutaciones que ocurren a los serotipos de $E$. coli han causado resistencia a los antimicrobianos lo 
que ha llevado a ocupar un papel importante en la incidencia y letalidad de las infecciones extraintestinales (Russo y Johnson, 2000; Breland et al., 2017).

\section{Epidemiología Escherichia coli}

Descripción inicial de "Colibacterium comuna "por Theodor Escherich en 1886, Alphonse Lesage en 1968 postuló que esta especie comprende cepas, así como variantes con diferente potencial patógeno, desde entonces, se han distinguido $E$. coli no patógena de cepas intestinales o extraintestinales, basándose en el tipo de infección y factores de virulencia que son importante en la patogénesis, estos marcadores o síntomas permiten diferenciar de E. coli de cepas gastrointestinales y para diferenciarlos de E. coli no patógena y de ExPEC (Kapper et al., 2004; Kolher y Dobrindt, 2011).

Las bacterias E.coli extraintestinales patógenas (ExPEC) son patógenos facultativos que pertenecen a la flora intestinal normal de una determinada fracción de la población sana donde viven como comensales (bacterias que comparten con otras el mismo órgano sin competir), la genómica comparada y los estudios epidemiológicos aplicados para estudiar la diversidad genómica, los marcadores y los rasgos fenotípicos pueden respaldar la discriminación de diferentes patotipos de E. coli (Kolher y Dobrindt, 2011).

La diferenciación confiable entre las variedades comensales y las cepas de $E$. coli son un requisito previo para la evaluación del riesgo, estudios epidemiológicos y ecológicos, así como para la población genética, la tipificación bacteriana es el análisis de los serogrupos somáticos, capsulares y flagelares (O: K: H) (Monroy et al., 2005). Para ExPEC, presenta variantes altamente virulentas con fenotipos epidemiológicamente vinculado con la enfermedad, se puede asignar a un límite número de serogrupos $\mathrm{O}$ y conjuntos de genes de virulencia (Tabla 1) (Kapper et al.,2004). 
Tabla 1. Factores de Virulencia extraintestinales patógenas (ExPEC)

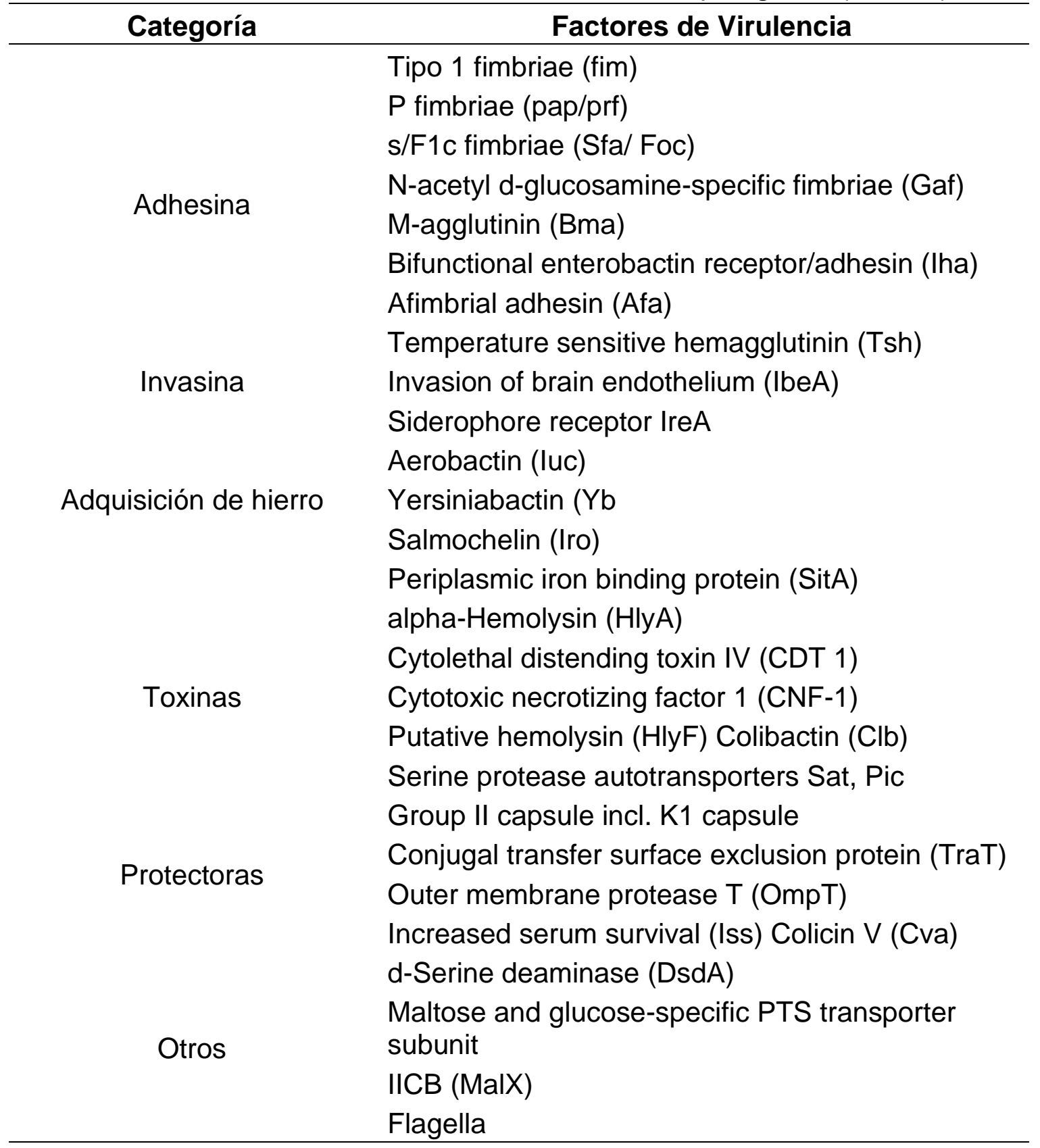

Fuente: Kepper et al., (2004)

\section{Escherichia coli PATOGÉNICA AVIAR}

Escherichia coli patogénica aviar (APEC) es un importante patógeno en la industria avícola, son consideradas miembros patogénicos de la Escherichia coli extra intestinal. Las APEC pueden infectar a pollos de engorde, pavos y gallinas en 
postura, las infecciones son consideradas como colibacilosis, induciendo a una amplia gama de infecciones localizadas y sistémicas, siendo una de las principales causas de mortalidad y morbilidad asociadas con las pérdidas económicas en la industria en todo el mundo (Zhuang et al., 2014).

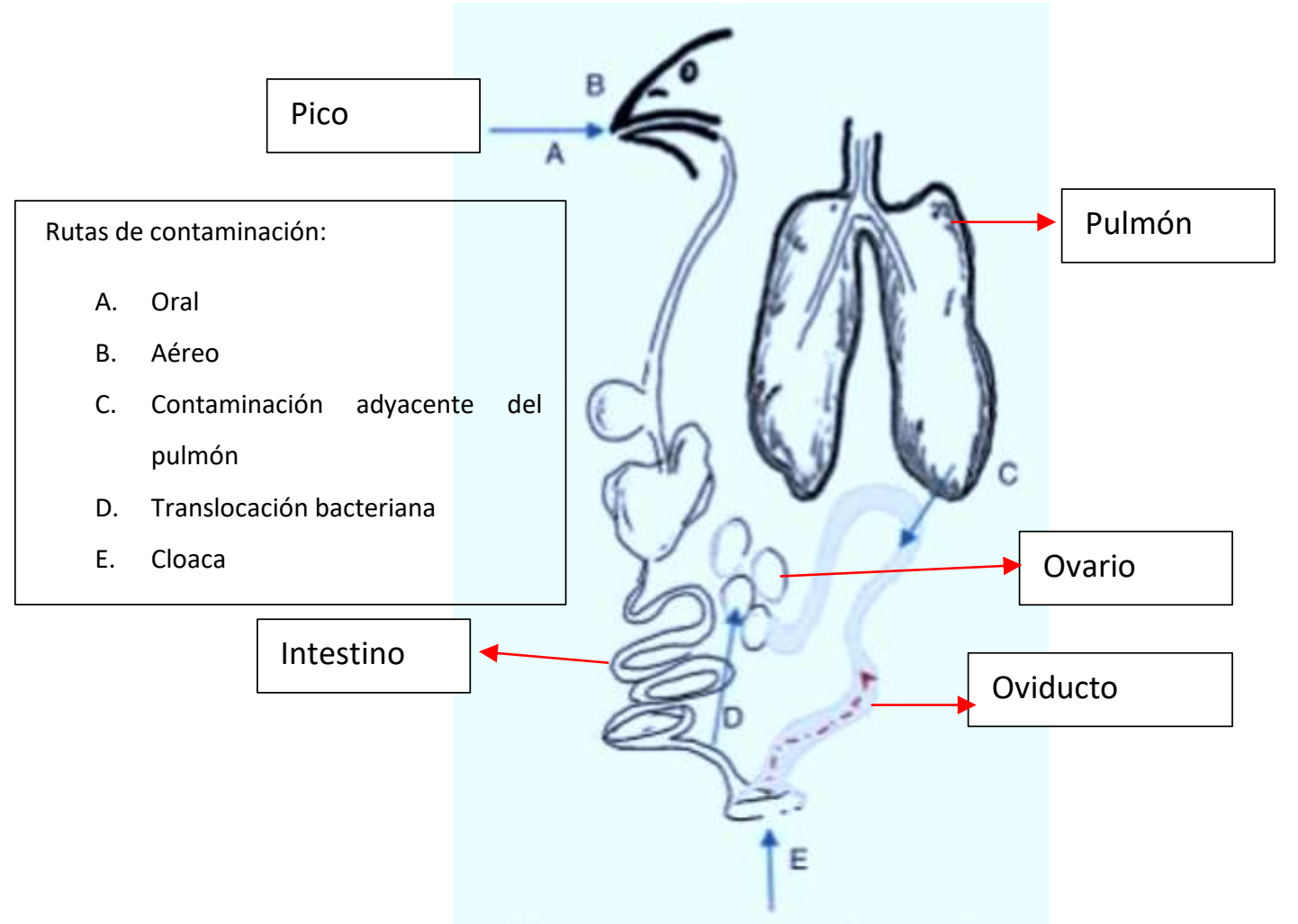

Figura 3. Rutas de Infección APEC

Fuente: Lutful et al ., (2017)

La mayoría de las enfermedades asociadas a APEC son secundarias debido a factores ambientales y predisposición del huésped, por lo tanto, las pérdidas debidas a estas enfermedades pueden reducirse considerablemente controlando estos factores, hoy las APEC se reconocen como patógenos primarios en lugar de una consecuencia de infecciones virales o inmunosupresoras, el conocimiento de APEC y su patogénesis es limitado, debido a su gran diversidad y plasticidad genética (Colliwngood et al., 2014).

La contaminación de las aves con E. coli ocurre en las primeras horas después de la eclosión, las cepas se multiplican rápidamente en el intestino y se pueden adquirir 
durante la vida, la contaminación vertical resulta de la transmisión de las reproductoras, en el momento de la salida del huevo por la cloaca, o in ovo, como resultado de la salpingitis, la contaminación horizontal ocurre por contacto con otras aves, a través de las heces, agua contaminada y alimento o por inhalación de partículas presentes en el polvo que pueden contener hasta $10^{6}$ UFC de bacterias por gramo (Dho y Morris, 1999).

La prevalencia de infecciones por E. coli es alta en gallinas ponedoras, aunado a esto, también ocasionan pérdidas de inversiones enfermedades como salpingitis y demás infecciones del tracto reproductivo, que incluyen peritonitis y salpingoperitonitis (SPS) (Collingwood, 2016). La mortalidad en pollos recién eclosionados suele atribuirse a infecciones por APEC, mortalidad de hasta $20 \%$, las aves que no muestran signos evidentes de infección pueden ser descartadas en el momento del sacrificio. Anteriormente se creía que las infecciones por E. coli en pollos eran secundarias a enfermedades como la enfermedad de Newcastle o micoplasmosis, sin embargo, ahora se reconoce que las infecciones por APEC pueden ser infecciones primarias, debido a factores predisponentes como el estrés, exposición a amoníaco y polvo, agua contaminada, razas modernas de rápido crecimiento.

\section{SÍNDROME DE PERITONITIS, SALPINGITIS Y PERISALPINGITIS POR Escherichia coli EN GALLINAS REPRODUCTORAS}

La bacteria $E$ coli es considerada como el agente etiológico que causa en alto grado salpingitis y peritonitis en gallinas, puede infectar el aparato reproductivo, la infección temprana es asintomática, es la responsable de las altas mortalidades embrionaria en las plantas de incubación. El genoma de E. coli tiene un alto grado de plasticidad, de los muchos aislamientos secuenciados completamente, comparten un núcleo central genómico de alrededor de 2000 genes y un genoma accesorio denominado pan-genoma, que presenta más de 18,000 genes, permitiendo alto grado de flexibilidad y adaptación a través de la transferencia 
horizontal de genes (Touchon et al., 2009). En el estudio realizado por Ewern et al., (2004), se evaluaron los principales serogrupos aislados en la colisepticemia de la industria avícola, encontrando la distribución de serogrupos 01 (6\%), O2 (28\%) y $\mathrm{O} 78(14.7 \%)$ y comensales $(50.4 \%)$. Las gallinas presentaban mayor mortalidad en el último tercio de la etapa de producción y las lesiones macroscópicas prevalentes eran peritonitis, salpingitis aerosaculitis, pericarditis, perihepatitis.

Se reportan tres rutas de infección del APEC: El ascenso de las bacterias por la cloaca al oviducto, infección por el tracto respiratorio y colonización del tracto gastrointestinal (Figura 4). Se describen tres pasos de la bacteriemia: Colonización, adquisición de nutrientes e inmunoevasión: 1- En la colonización se encuentran, adhesinas (fimbrias: Tipo 1, Curly, P y YqiStg y adhesina autotrasportadora, AatA) que son proyecciones que se adhieren a la mucosa del hospedero y produce la colonización. 2- Para la adquisición de nutrientes para su sobrevivencia, se hace secuestro iones férricos de las proteínas ligadoras de este mineral, siendo fundamentales para la respiración y síntesis de ADN. Los factores de virulencia tienen afinidad por quelantes de hierro como lo son aerobactina, salmochelin, sistema sit, proteína trasportadora ChuA, que se encargan del crecimiento bacteriano dentro de los fluidos biológicos del hospedador, que tienen bajas concentraciones de hierro. La inmunoevasión evita que la APEC sea atacada por fagocitos y leucocitos del hospedero, a partir de la capsula de polisacárido K1 resistencia sérica degenerando la vía secretora, estos factores de virulencia ayudan a generar patogénesis, causando la enfermedad en las gallinas reproductoras (Lutful et al., 2017).

Hay varias rutas de entrada para infectar el tracto reproductivo de las hembras, uno de ellas es la contaminación ascendente por las heces contaminadas en la cloaca que pueden contaminar la vagina y las secciones restantes del oviducto ya que la producción intensiva de huevos y la actividad estrogénica asociada predisponen a las gallinas al relajar el esfínter entre la vagina y la cloaca, facilitando que oviducto que afectado por salpingitis, también puede producirse la invasión peritoneal por 
APEC, lo que puede conducir a salpingoperitonitis (Landman y Cornelissen, 2006; Barnes et al., 2008).

La salpingitis afecta a las aves adultas, en producción, cuando ya se ha producido la citodiferenciación del oviducto por el proceso hormonal, la diferencia en las propiedades de adherencia, puede estar asociada con el epitelio maduro, siendo probable que ciertas proteínas presentes en la membrana celular permitan la unión con E. coli (Brand y Nalvandov, 1980).

La infección del tracto respiratorio de las aves por APEC ocurre a través de la inhalación de partículas y bacterias de aerosol contaminado, que una vez en el pulmón, son atacadas por los macrófagos, primera línea de defensa del organismo y medio de diseminación de la bacteria, luego son fagocitadas por células epiteliales auriculares e infundibulares de la región parabronquial. El saco aéreo no tiene mecanismos de defensa celular conocidos y depende de la afluencia inflamatoria de neutrófilos, como la primera línea de defensa celular, por tanto, las regiones de intercambio gaseoso de los pulmones y sacos aéreos son vulnerables a la colonización bacteriana. La región aire-capilar del pulmón, es un sitio importante de entrada de $E$. coli en el torrente sanguíneo de las aves, después de colonizar tráquea y sacos aéreos se considera que los siguientes órganos afectados son el pericardio e hígado causando bacteriemia (Dho y Morris, 1999).

\section{RESPUESTA INMUNE DEL HOSPEDERO}

Diversos niveles de defensa del hospedador se desarrollan, dependiendo del número de organismos que ingresa y de la virulencia que presenten, si el tamaño del inoculo y la virulencia son bajos, los fagocitos tisulares son capaces de eliminar la bacteria, si es mayor virulencia inducen una reacción inmunitaria específica y adaptativa en el animal (Tabla 2) (Kindt et al., 2007). 
Tabla 2. Reacciones inmunitarias del hospedador a la infección bacteriana y mecanismos de evasión de las bacterias

\begin{tabular}{|c|c|c|}
\hline $\begin{array}{l}\text { Proceso } \\
\text { infeccioso }\end{array}$ & $\begin{array}{l}\text { Defensas del } \\
\text { hospedador }\end{array}$ & $\begin{array}{l}\text { Mecanismos de evasión de las } \\
\text { bacterias }\end{array}$ \\
\hline $\begin{array}{l}\text { Fijación de la célula } \\
\text { hospedadora }\end{array}$ & $\begin{array}{l}\text { Bloqueo de la } \\
\text { fijación de } \\
\text { anticuerpos lgA } \\
\text { secretorios }\end{array}$ & $\begin{array}{c}\text { Secreción de proteasas que escinden } \\
\text { los dímeros de IgA secretoria } \\
\text { (Neisseria meningitidis, } N \text {. } \\
\text { gonorrhoaeae, Hameophilus } \\
\text { influenzae) Variación antigénica de las } \\
\text { estructuras de fijación (pelos de } N \text {. } \\
\text { gonorrhoaeae) }\end{array}$ \\
\hline \multirow[t]{2}{*}{ Proliferación } & $\begin{array}{l}\text { Fagocitosis } \\
\text { (opsonización } \\
\text { mediada por } \\
\text { anticuerpo y C3b) }\end{array}$ & $\begin{array}{c}\text { Producción de estructuras de } \\
\text { superficie que inhiben las células } \\
\text { fagocíticas. Mecanismos para la } \\
\text { supervivencia dentro de las células } \\
\text { fagocíticas inducción de apoptosis en } \\
\text { los macrófagos }\end{array}$ \\
\hline & $\begin{array}{l}\text { Lisis mediada por } \\
\text { complemento y } \\
\text { reacción } \\
\text { inflamatoria } \\
\text { localizada }\end{array}$ & $\begin{array}{c}\text { Resistencia generalizada de las } \\
\text { bacterias Gram }{ }^{+} \text {a la lisis mediada por } \\
\text { complemento } \\
\text { Prevención de la inserción de } \\
\text { complejos de ataque de membrana } \\
\text { por la cadena lateral larga del LPS de } \\
\text { la pared celular }\end{array}$ \\
\hline $\begin{array}{l}\text { Invasión de los } \\
\text { tejidos del } \\
\text { hospedador }\end{array}$ & $\begin{array}{l}\text { Aglutinación } \\
\text { mediada por } \\
\text { anticuerpo }\end{array}$ & $\begin{array}{c}\text { Secreción de la elastasa que } \\
\text { desactiva los componentes C3a y C5a } \\
\text { (pseudomonas) }\end{array}$ \\
\hline $\begin{array}{l}\text { Lesión de las } \\
\text { células } \\
\text { hospedadoras } \\
\text { inducidas por } \\
\text { toxinas }\end{array}$ & $\begin{array}{l}\text { Neutralización de } \\
\text { la toxina de } \\
\text { anticuerpo }\end{array}$ & $\begin{array}{l}\text { Secreción de la hialuronidasa, que } \\
\text { intensifica la invasividad bacteriana }\end{array}$ \\
\hline
\end{tabular}

Fuente: (Kindt et al., 2007)

\section{HALLAZGOS MACROSCÓPICOS}

La infección por E. coli incluye septicemia, pericarditis subaguda, aerosaculitis, salpingitis y peritonitis, muchos serotipos de esta bacteria se encuentran en las aves de corral, pero solo APEC posee factores de virulencia específicos y es capaz de 
causar salpingitis y peritonitis, esta última se da generalmente por una infección sistémica o ascendente desde la cloaca al oviducto (Landman y Cornelissen, 2006). Estudios reportaron que la APEC, produce exudados fibrinosos en la vagina y en el oviducto (itsmo, útero), ovarios atrofiados y mucosa del oviducto engrosada y edematosa (Ozaki y Murase 2009; Jordan et al., 2005; Roberts 2011) (Figura 4).

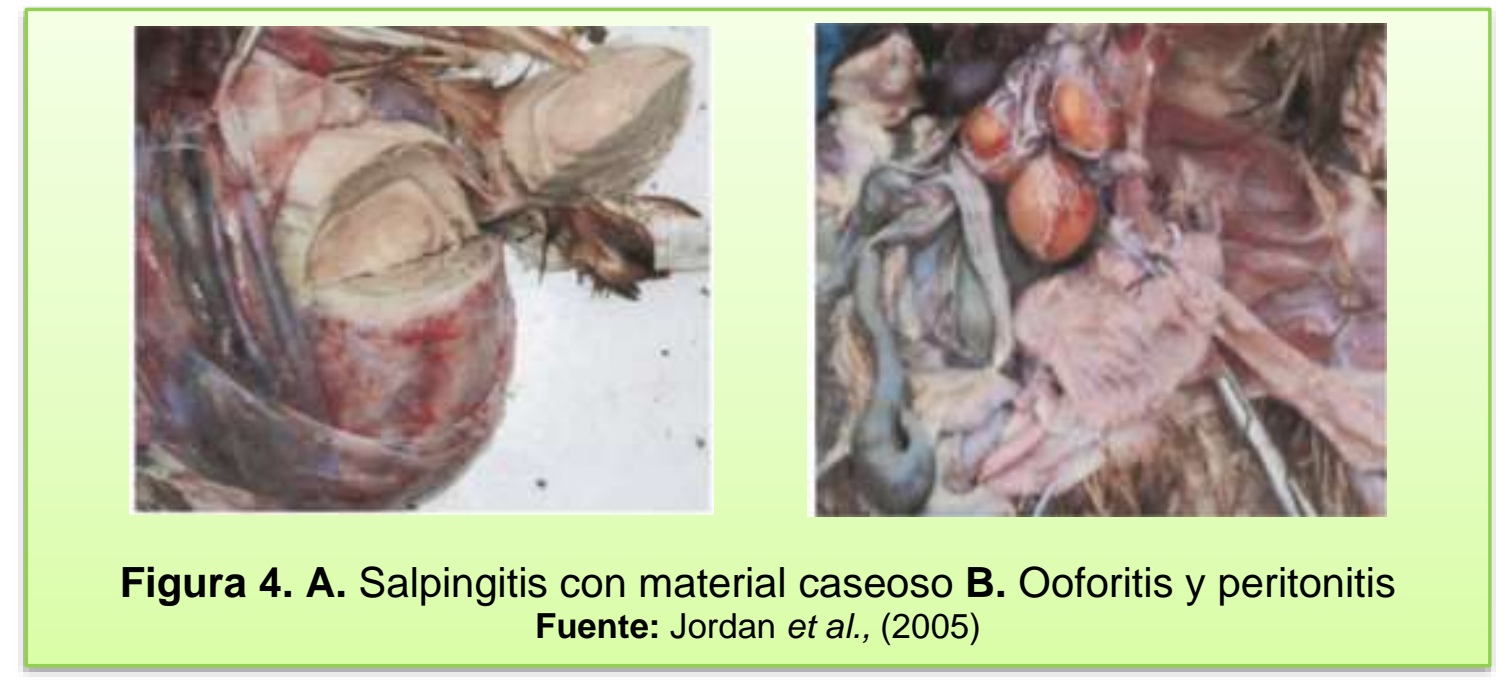

Los procesos inflamatorios causados por APEC, lleva a necrosis y acumulación de fibrina en los tejidos; con modelos de infectados experimental con E. coli 078 en reproductoras pesadas, presentaron resultados de las principales lesiones que se causa en el tejido ovárico (Atul y Kariyawasam, 2014). En la Figura 5 se muestra la histología representativa de tejidos ováricos de aves infectadas con control y APEC078. (A) ovario con textura histológica normal, como la membrana perivitelina (PVM) seguida de las células de la granulosa (GC), la teca interna (TI) y la capa externa de la teca (TE). (B) La sección de ovario presenta plegamiento y engrosamiento de la membrana perivitelina (flecha negra) y el reemplazo de células de la granulosa por células inflamatorias (flecha blanca). (C) Versión ampliada de una porción rectangular que se muestra en la Figura $5 \mathrm{~B}$; numerosas colonias bacterianas (indicadas por una punta de flecha).

Los resultados de los cortes, Figura 6: (A) sección de oviducto de textura histológica normal, como las glándulas de la mucosa (MG) cubiertas por un epitelio ciliado columnar de simple a pseudoestratificado (CE). (B) Sección de oviducto de una 
gallina que muestra epitelio hipersecretor con pérdida de borde ciliado y acumulación de material edematoso en la luz (flecha negra) caracterizada por infiltración de neutrófilos (flecha blanca).
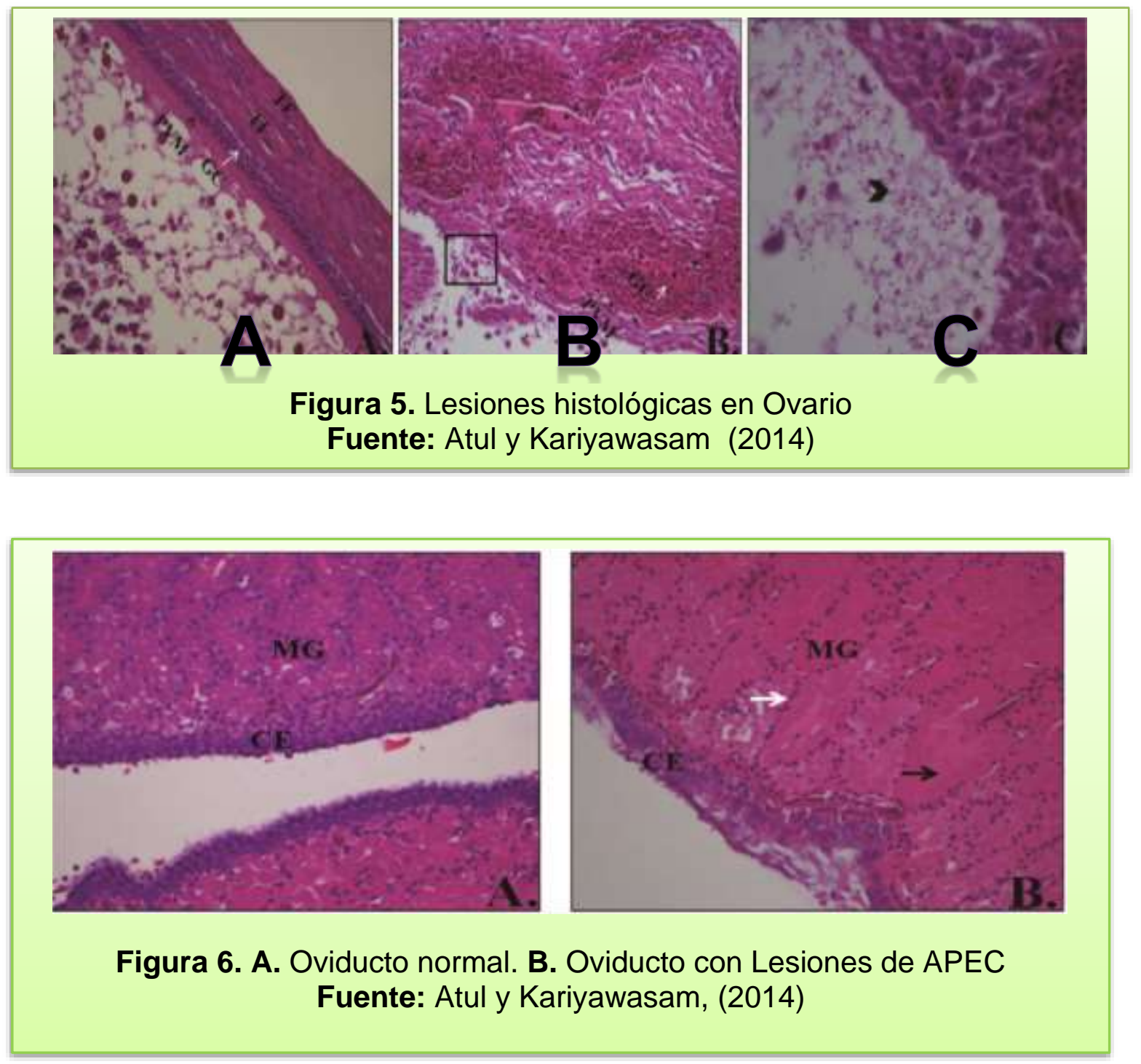

\section{EL EFECTO SOBRE LA PRODUCCIÓN YTRASMISIÓN A LA PROGENIE}

La infección del oviducto por E. coli causa alta mortalidad en las reproductoras, disminución de la producción, contaminación de huevos fértiles, aumento en la mortalidad embrionaria o en la primera semana de vida del pollo de engorde (Barnes 
et al., 2008). La entrada de E. coli tiene lugar en diferentes sitios en el sistema de producción, hay transmisión horizontal en incubadoras y línea de procesamiento en el criadero que puede multiplicar y transmitir entre polluelos, el transporte de pollos y la higiene de la granja también son puntos críticos que presentan un riesgo (Yassin et al., 2009). La transmisión vertical es una importante ruta de genes que albergan resistencia a los antimicrobianos (Olsen et al., 2012).

Se considera que la transmisión vertical de agentes infeccioso generalmente ocurre por el oviducto antes de la formación de la cáscara del huevo, E. coli es capaz de penetrar la cáscara de huevo. Se ha demostrado la transmisión vertical para otras especies bacterianas tales como Salmonella enterica y Enterococcus faecalis (Landman et al.,1999), lo ha demostrado la patogénesis de la contaminación del huevo, que después de presentar una diseminación sistémica, las bacterias también pueden acceder al oviducto a través de la infección ascendente de la cloaca, posible ruta de contaminación del huevo con Salmonella y también a través de la cáscara, la contaminación de la superficie puede ser por la excretas o ser el resultado de la infección de la vagina; otra ruta posible es por contaminación directa de la yema y sus membranas, albúmina, la cáscara del huevo que se originan de la infección del ovario, infundíbulo, magno, istmo y glándula del cascarón, la Salmonella depositada en la albúmina y en la membrana vitelina es capaz de sobrevivir y crecer en el ambiente antibacteriano, puede migrar y penetrar la membrana vitelina para llegar a la yema, que es rica en nutrientes (Gantois et al., 2009).

Factores como la diferencia de: temperatura, $\mathrm{pH}$, humedad entre el huevo y suspensión bacteriana y la calidad de la cáscara pueden influir en la tasa de penetración bacteriana a través de ella. Es de anotar que la calidad de la cáscara disminuye durante la vida productiva de la gallina, lo que resulta en una mayor tasa de huevos contaminados en aves mayores de 45 semana. También se ha reportado que la deposición de la cutícula, es un factor que influye en la tasa de penetración de la bacteria por cáscara de huevo, mientras otros factores, como su grosor y número de poros no contribuyen significativamente en esta tasa (Gantois et al., 2009). 
Se ha encontrado una mayor prevalencia de colonización de $E$. coli en el huevo de ponedoras de piso comparados los que son puestos en nido, esto podría sugerir que excluir los primeros de la nacedera podría minimizar la colonización de los pollos recién nacidos con $E$. coli, además, se concluyó que pollitos de padres con mayor edad presentaba mayor riesgo de contaminarse en comparación con los hijos de padres jóvenes, puesto que la calidad de la cascara del huevo podría influenciar (Poulsen et al., 2017).

El método diagnóstico de la $\mathrm{O}$ serotipificación es de uso frecuente, es una herramienta valiosa en la evaluación epidemiológica, el análisis de riesgos y la prevención, esta serotipificación molecular hace referencia a ensayos que se dirigen a genes específicos del grupo $O$ y que se encuentran dentro de los grupos genéticos del E. coli O-antígeno y antígeno $\mathrm{H}$ que codifican para los diferentes tipos flagelares. El método rápido como ELISA, basado en $E$. coli, para la detección de anticuerpos contra dos serotipos patógenos importantes de E. coli: O78: K80 y O2: $\mathrm{K} 1$, otro ELISA se basó en el antígeno fimbrial, ambos tienen un valor limitado porque solo pueden detectar tipos de APEC homólogo (Fratamico et al., 2016).

Los métodos de subtipificación que permiten la diferenciación de E. coli más allá del nivel de especie y subespecie son críticos para determinar la fuente de los brotes y establecer vías de transmisión, varios métodos basados en el genotipo, fenotipo y para subtipificación de E. coli se utilizan antígenos "O" y "H", y marcadores de polimorfismo de nucleótidos simples (SNPs), además se especifica la relación con otros genes que ocasionan virulencia (Tabla 3).

\section{FACTORES DE RIESGO}

El riesgo de colibacilosis aumenta con la infección en el medio ambiente y un mal manejo de la bioseguridad en la granja, la mala higiene del galpón, del personal que maneja las aves, no realizar los lavados correspondientes antes del manejo, no realizar fumigaciones rutinarias a las camas de los galpones para disminuir la carga bacteriana que puede predisponer a la enfermedad. Un ambiente desfavorable, con 
exceso de amoníaco o polvo, hace que el sistema respiratorio sea más susceptible a las infecciones por APEC a través de la decilización del tracto respiratorio superior, por ello es importante tener buena limpieza de las mallas, en los nidos, lámparas y todos los materiales que se encuentren en el galpón, el estado de la cama puede ser un riego de colonización rápida de la bacteria (Barnes y Gross, 1997). Por otro lado, un factor a tener en cuenta es la sobrepoblación, los cambios bruscos que se dan en el momento de la apertura o comienzo de la producción de las aves, puesto que entran en contacto directo con los machos, si no se maneja bien su densidad por metro cuadrado, en estos casos hay un sobre-apareamiento de las gallinas causando laceraciones y aumentando el riesgo de celulitis que conllevan a la septicemia. Otros factores que deben tenerse en cuenta son la duración de la exposición, la virulencia propia de la cepa, la raza y el estado inmune del ave. (Poulsen et al., 2017).

El consumo del agua en los animales es un factor crítico y esta debe cumplir con estándares de calidad aceptados, con un buen manejo para que las concentraciones de bacterias totales y de coliformes no excedan 100 y 500 UFC/100ml respectivamente. Las deficiencias severas de los nutrientes pueden deteriorar la inmunidad del hospedero y por ende disminuir resistencia a las enfermedades, es importante evaluar las condiciones de presentación e higiene en el alimento puesto que puede alterar la inmunidad del intestino y producir una entrada invasiva de bacterias patógenas que produzcan daño a las aves. El manejo que se le da a la recogida del huevo de piso es importante para disminuir el riesgo de contaminación y colonización bacteriana que posteriormente lleva a muertes embrionaria o contaminación de la máquina de nacimiento (Barnes y Gross, 1997).

Diferentes frentes deben ser abordados para lograr una eficaz prevención de las enfermedades, en primer lugar disminuir la contaminación ambiental para bajar el contacto con infecciones respiratorias, teniendo una adecuada infraestructura con zonas limpias y sucias, zona para cambio de ropa y lavado de manos, sin dejar de lado un buen manejo de las heces y el control de plaga; es de vital importancia 
factores como la densidad, la humedad, la ventilación, el polvo y el amoniaco que deben ser controlados estrictamente (Dho y Fairbrother1997).

Tabla 3. Métodos de diagnósticos utilizados para determinar la E. Coli

\begin{tabular}{|c|c|c|c|c|}
\hline Métodos & 0 & $\mathbf{H}$ & $\begin{array}{c}\text { Relación con } \\
\text { genes virulentos }\end{array}$ & SNPs \\
\hline Serotipado de $\mathrm{O} / \mathrm{H}$ inmunológico & $x$ & $x$ & & \\
\hline Tipificación de bacteriófago & & & & $x$ \\
\hline Electroforesis con enzimas multilocus & & & & $X$ \\
\hline MALDI-TOF & & $x$ & & $x$ \\
\hline $\begin{array}{l}\text { Polimorfismo de longitud de restricción } \\
\text { (RFLP) }\end{array}$ & $x$ & $x$ & $\mathrm{x}$ & \\
\hline $\begin{array}{l}\text { Ensayo de suspensión basado en } \\
\text { liminex }\end{array}$ & $x$ & & & \\
\hline Mapeo óptico & & & $x$ & $x$ \\
\hline Ribotipificado & & & & $x$ \\
\hline $\begin{array}{l}\text { Análisis de repetición en tándem de } \\
\text { números variables de moltilocus (MLVA) }\end{array}$ & & & & $x$ \\
\hline Electroforesis en gel de campo pulsado & & $x$ & & $x$ \\
\hline $\begin{array}{l}\text { Mecanografía de secuencia de } \\
\text { moltilocus }\end{array}$ & & & & $x$ \\
\hline PCR de alto rendimiento en tiempo real & $x$ & $x$ & $x$ & \\
\hline PCR multiplex & $x$ & $x$ & $x$ & \\
\hline $\begin{array}{l}\text { Secuenciación completa del genoma y } \\
\text { análisis de SNP }\end{array}$ & $x$ & $\mathrm{x}$ & $\mathrm{x}$ & $\mathrm{x}$ \\
\hline Perfiles de genes de virulencia & & & & $x$ \\
\hline Microrray & $x$ & $x$ & $x$ & $x$ \\
\hline $\begin{array}{l}\text { NeoSEEK TM (PCR espectroscopia de } \\
\text { masa) }\end{array}$ & $x$ & $x$ & $\mathrm{x}$ & $x$ \\
\hline CRISPRs & & & & $\mathrm{X}$ \\
\hline
\end{tabular}

Adaptada de (Fratamico et al., 2016). *(SNPs) Marcadores de polimorfismo de nucleótidos simples. *Antígenos "O" y "H. Métodos basados en fenotipo y genotipo. 


\section{VACUNAS}

Las aves responden a las vacunas desarrollando respuestas humorales y celulares, la bolsa de Fabricio y el timo sirven como los principales órganos linfoides del sistema inmune, las células $B$ usan inmunoglobulinas de superficie como receptores de antígenos y se diferencian en células plasmáticas para secretar anticuerpos, se producen tres clases de anticuerpos: $\lg M$, $\lg G$ (también llamado $\lg Y$ ) e $\lg A$, el éxito de la respuesta a la vacuna en una parvada a menudo se controla demostrando un aumento en el título de anticuerpos a los pocos días de la vacunación (Ghunaim et al., 2014).

Los esfuerzos para encontrar una vacuna eficaz contra las APEC, se han centrado en el uso de bacterinas, luego se dieron las vacunas in vivo y posteriormente las de subunidades, varios obstáculos al intentar diseñar una vacuna es la de inducir protección cruzada contra varios serogrupos APEC además deben ser de uso en el agua potable, el alimento, in ovo o spray, por último, se debe administrar a aves jóvenes para que desarrolle una inmunidad protectora (Ghunaim et al., 2014).

Otros estudios probaron la activación por ultrasonidos: $\mathrm{K} 1$ y O78: vacunas $\mathrm{K} 80$ en adyuvante de hidróxido de aluminio, estas vacunas inactivadas proporcionaron una mejor protección que las bacterinas preparadas con calor, formaldehído o radiación (Melamed et al., 1991). Resume, que son varios los factores desempeñan un papel en la determinación de la eficacia de la vacuna como son: serogrupo o serotipo de E. coli, tipo de adyuvantes, el método utilizado para inactivar las bacterias, la ruta de administración (Ghunaim et al.,2014).

Las vacunas de subunidades demuestran mayor resultado en la inducción de un sistema inmunitario protector, especialmente contra la exposición heteróloga en comparación con vacunas inactivadas, con la adición de nuevas secuencias genómicas de APEC añadidas, el descubrimiento de otros factores de virulencia busca el camino para el desarrollo de una nueva subunidad de vacunas (Tabla 4). 
Tabla 4. Tipos de vacunas de subunidades

\begin{tabular}{|c|c|c|c|c|c|}
\hline Antígeno & Vía & $\begin{array}{c}\text { Edad 1a } \\
\text { Vacunación } \\
\text { (Días) }\end{array}$ & $\begin{array}{c}\text { Edad 2a } \\
\text { Vacunación } \\
\text { (Días) }\end{array}$ & Ruta & $\begin{array}{l}\text { Edad } \\
\text { (Días) }\end{array}$ \\
\hline Aerobactina & $\mathrm{Im}^{\mathrm{a}}$ & $\mathrm{N} / \mathrm{A}$ & $\mathrm{N} / \mathrm{A}$ & Aerosol & 1 \\
\hline Iromps & $I v^{b}$ & 18 & $N / A$ & Saco Aéreo & 18 \\
\hline 01, O2, O78 Pilli & SC & 28 & 42 & Saco Aéreo & 56 \\
\hline Fimam $^{d}$ & $\mathrm{Im}^{\mathrm{d}}$ & $\mathrm{N} / \mathrm{A}$ & $N / A$ & Saco Aéreo & 21 \\
\hline $\begin{array}{l}\text { Recombinat } \\
\text { Fimh }\end{array}$ & $\mathrm{Im}^{\mathrm{c}}$ & 11 & $N / A$ & $\begin{array}{c}\text { Saco Aéreo } \\
\text { Aerosol }\end{array}$ & 14 \\
\hline $\begin{array}{l}\text { Recombinat } \\
\text { Papg }\end{array}$ & $\mathrm{IM}$ & 11 & $N / A$ & Saco Aéreo & 14 \\
\hline Recombinat luat & $\mathrm{Im}^{\mathrm{c}}$ & 11 & $N / A$ & Saco Aéreo & 14 \\
\hline Recombinat Iss & $\mathrm{IM}$ & 14 & $N / A$ & Saco Aéreo & 28 \\
\hline $\begin{array}{c}\text { Recombinat } \\
\text { Papgii }\end{array}$ & $\mathrm{IM}$ & 10 & $\mathrm{~N} / \mathrm{A}$ & $\begin{array}{c}\text { Saco Aéreo } \\
\text { Aerosol }\end{array}$ & 34 \\
\hline
\end{tabular}

Fuente: Ghunaim et al., (2014)

Estudios realizados con vacunas basadas en fimbrias en gallinas reproductoras, que vacunadas con la proteína, su progenie resistieron tanto cepas homologas (O78), como heterólogas (O1, O2 APEC), los anticuerpos anti pilus pueden prevenir la adhesión de $E$. coli patógena a las superficies de las células huésped, en consecuencia, Gyimah y Panigrahy, (1986) desarrollaron y probaron una vacuna de pilis de O coli O1: K1 emulsionada en aceite contra la colibacilosis en pollos, esta contenía $116 \mu \mathrm{g}$ o $29 \mu \mathrm{g}$ de proteína de fimbria y se aplicó subcutánea (SC) dos veces, a las 4 y 6 semanas de edad, a las 8 semanas de edad los pollos fueron infectados con $E$. coli con una inyección de saco intra-aéreo, los vacunados presentaban menor mortalidad, y lesiones después de ser infectadas que es un homólogo de APEC en comparación con los no vacunados (control) (Ghunaim et al., 2014). 
Las vacunas vivas atenuadas son de administración masiva por eso las hace más atractivas y adecuadas a la industria de pollos de engorde en lugar de vacunas que están disponibles solo para administración individual, los primeros estudios que se utilizaron en cepas avirulentas vivas, fue APEC O78 del serogrupo K1 se usó para inmunizar pavos a los 7 y 14 días de edad por vía intramuscular (IM)o intratraqueal (IT), luego fueron infectados con un homólogo de las bacterias por vía IV usando 108 UFC, 10 días después de la última vacunación dieron como resultado un 88\% de disminución en la mortalidad 77\%para el tratamiento IM en comparación con el control. Aunque la inmunización redujo la mortalidad, la mayoría de las aves que sobrevivieron a la enfermedad desarrollaron polisinovitis (Ghunaim et al., 2014).

\section{ANÁLISIS Y DISCUSIÓN}

Los mecanismos subyacentes a la evolución y aparición de nuevos patógenos bacterianos, no son suficientes, para explicar la evolución de las cepas patogénicas de Escherichia colise ha determinado que es una bacteria con una gran diversidad hereditaria con genes polimórficos que presentan un ambiente muy diverso lo cual dificulta las investigaciones sobre el tema, este polimorfismo define los factores de virulencia y los genes responsables de la diferenciación que presenta cada cepa, que son los responsables de la supervivencia del patógeno dentro del hospedero, los estudios y revisiones presentados, dan a entender acerca de los tres tipos de contaminación que puede presentar el ave, ya sea por el ingreso por vía respiratoria, translocación bacteriana en el intestino, o por el ingreso ascendente de la cloaca al oviducto, conllevando a su muerte y dando hallazgos en necropsias como pericarditis, perihepatitis, ooforitis, salpingitis, o en general una poliserositis. Dado que la industria avícola invierte bastante capital es importante manejar los factores de riesgo que puedan llevar a producir brotes de E. coli por esos buenas prácticas, bioseguridad y control de higiene dentro de las instalaciones son las recomendaciones en las cuales que se enfocan los investigadores. 
Al no evaluar los posibles riesgos de contaminación por las APEC, se presentan consecuencias que conllevan anormalidades en los nacimientos, baja tasa de natalidad, aumento de mortalidad en pollitos de un día, además de reclamos de los clientes. Otros métodos de prevención de la enfermedad es la vacunación, que forma parte integral de los protocolos de gestión de salud de los lotes, los sistemas de administración de vacunas incluyen inyección in ovo, aerosol, pulverización, agua potable, colirio e inyección en la membrana del ala, el intento por crear una vacuna ha sido el esfuerzo por muchos investigadores, al entender la genoma de la bacteria es complicado por las diferentes cepas que pueda presentar un animal, además es necesario utilizar una medio de aspersión que le brinde inmunidad a las aves y al entorno para que la vacuna tenga mayor efectividad.

\section{CONCLUSIONES Y RECOMENDACIONES}

Es de vital importancia manejar lo puntos de riesgo que presenta la granja, para disminuir la contaminación de las aves y de subproductos, manteniendo buenos protocolos de bioseguridad, sanitización y ventilación de galpones, buen manejo de desechos de aves, tiempos de retiros entre lotes, realizando microbiología del agua y materias primas, capacitaciones a los operarios que manejen las aves.

Realizar toma de muestras rutinaria a los elementos de los galpones, agua, alimento y mano de los operarios que manipulan las aves.

En el momento que se presenten altas mortalidades, las visitas a los galpones deben ser exhaustiva, realizar una buena anamnesis, desde la entrada al galpón, observando el manejo de los galponeros con el alimento y el entorno, revisar que se encuentre en orden y limpiezas de los implementos de trabajo del operario; después revisar el comportamiento de los animales en el momento de recibir el alimento, y desarrollar un análisis poblacional de las que estén lesionadas; si es posible se debe realizar un corral para separar las aves sanas de las que presentan signos de letargia y anorexia. 
Llevar un reporte de los casos presentados en la granja a partir de la fecha del evento, edad del lote, etapa de producción, alimento, operarios y lo correspondiente a los hallazgos de necropsias, para evaluar en qué momento se presenta la enfermedad, que la pudo haber desencadenado y así evaluar qué puntos críticos se están fallando dentro de la granja.

Al momento de presentar signos de una posible contaminación, lo apropiado es realizar un buen diagnóstico, evaluando los puntos críticos de las necropsias y análisis microbiológicos, y realizar una genotipificación de la bacteria, no quedarse solo con el aislamiento y antibiograma, puesto que la nuevas tecnologías facilita una mejor compresión secuenciación de ARN y los sistemas de análisis de células individuales utilizados junto con la biología de la infección tradicional, pueden ofrecer mayores posibilidades para el estudio de la patogénesis microbiana y la inmunidad a mayor escala, estos desarrollos informarán medidas de control de enfermedades, mejorarán el bienestar animal y producirán importantes conocimientos sobre la susceptibilidad de las aves de corral a la colibacilosis y las enfermedades asociadas. Se debe tener cuidado a la hora de administrar antibiótico a las aves, puesto que el polimorfismo y múltiples variables de los genes de la E. coli, pueden presentar una evolución y crear una bacteria altamente patógena con resistencia a antibióticos.

\section{REFERENCIAS BIBLIOGRÁFICAS}

1. Atul C., Kariyawasam S. An experimental infection model for Escherichia coli egg peritonitis in layer chickens. Bioone, 25-33. 2014.

2. Barnes J., Gross W. Colibacilosis. En: Calnek BM, (Ed). Diseases of poultry. 1997.

3. Barnes H., Nolan L., Vaillancourt J. Collibacilosis. Dissease poultry. 2008.

4. Brand J., Nalvandov A. Role of sex hormones in albumen secretion by the oviduct of chickens. Poult sci., 35 (3): 692-700. 1980. 
5. Breland J., Eberly R., Hadjifrangiskou M. An overview of two-component signal transduction systems implicated in extra-intestinal pathogenic E. coli infections. Frontiers in cellular and infection microbiology, 7: 162. 2017. doi: https://doi.org/10.3389/fcimb.2017.00162

6. Clermont O., Christenson J., Denamur E., Gordon D. The clermont Escherichia coli phylo-typing method revisted: improvent of specificity and detection of new phylo- groups. Environmetal Microbiology Reports, 58-65. 2013.

7. Collingwood C. Pathogenomic characterization of a novel, layer-associated avian pathogenic Escherichia coli. Doctor of philosophy Thesis, University of Liverpool. 2016.

8. Croxen M., Law R., Scholz R., Kenney K., Wlodarska M., Finlay B. Recent advances in understanding enteric pathogenic Escherichia coli. Clinical Microbiology Review, 822-880. 2013.

9. Dho-Moulin M., Morris-Fairbrother J. Avian pathogenic Escherichia coli (APEC). Vet. Res, 299-316. 1999.

10. Fratamico P., Debroy C., Liu Y., Needleman D., Baranzoni M., Feng P. Advances in molecular serotyping and subtyping of Escherichia coli. frontiers in microbiology. 2016. doi: https://doi.org/10.3389/fmicb.2016.00644

11. Gantois I., Ducatelle R., Pasmans F., Haesebrouck F., Gast R., Humphrey J., Van Inmerseel F. Mechanisms of egg contamination by salmonella enteritidis. FEMS Microbiol Rev. 2009.

12. Ghunaim H., Abu Madi, M., Kariyawasam, S. Advances in vaccination against avian pathogenic Escherichia coli respiratory disease: potentials and limitations. Vet Microbiol. 172 (1-2):13-22. 2014.

13. Gyimah, Panigraphy B. Adhesion receptor interaction mediating the attachment of pathogenic Escherichia coli to chicken tracheal epithelium. Avian Dissease, 1988.

14.Jordan F., Williams J., Wattret A., Jones T. Observations on salpingitis, peritonitis and salpingoperitonitis in a layer breeder flock. Veterinay Record, 573577. 2005. 
15. Kaas R., Friis C., Ussery D., Aarestrup F. Estimating variation within the genes and inferring the phylogeny of 186 sequenced diverse Escherichia coli genomes. BMC Genomics. 2012.

16. Kapper J., Nataro J., Mobley H. Pathogenic Escherichia Coli. Nat Rev Microbiol, 123-140. 2004.

17. Kindt T., Goldsby R., Osborne B. Inmunorreacción de las enfermedades infecciosas. En: T. Kindt R. Goldsby \& B. Osborne, Inmunología de kuby mcgraw hillniteramericana. 455. 2007.

18. Kolher C., Dobrindt U. What defines extraintestinal pathogenic Escherichia coli? International Journal of Medical Microbiology, 642-647. 2011.

19. Landman W., Feberwee A., Mekkes D., Veldman K., Mevius D. A study on the vertical transmission of arthropathic and amyloidogenic Enterococcus faecalis. Avian Pathology, 559-566. 1999.

20. Landman W., Cornelissen R. Escherichia coli salpingitis and peritonitis in layer chickens: an overview. Tijdschrift voor Diergeneeskunde, 814-822. 2006.

21. Lutful M., Sikder M., Jahanjier A., Sucharit N. Colibacillosis and its impact on egg production. En: P. hester, Egg innovations and strategies for improvements, 523 p. 2017.

22. Melamed, D., Leitner, G., Heller, E. A vaccine against avian colibacillosis based on ultrasonic inactivation of Escherichia coli. Department of Animal Sciences, Faculty of Agriculture, Hebrew University of Jerusalem, Rehovot, Israel. Avian Dis., 35 (1): 17-22. 1991.

23. Monroy M., Knobl T., Bottino J., Astolfi C., Piantino A. Virulence characteristics of Escherichia coli isolates obtained from broiler breeders with salpingitis. Comparative Immunology Microbiology Infectious Disease, 1-15. 2005.

24. Olsen R. H., Frantzen C., Christensen H., Bisgard M. An investigation on first week mortality in layers. Avian Diseases, 51-57. 2012.

25. Ozaki H., Murase T. Multiple routes of entry for Escherichia coli causing colibacillosis in commercial layer chickens. Journal Veterinary Medical Science, 1685-1689. 2009. 
26. Poulsen L., thofner I., bisgaard M., Cristensen P., Olsen R., Christensen H. Longitudinal study of trasmission of Escherichia coli from broiler breeders to broilers. Veterinary Microbiology. 2017.

27. Reid S., Herbelin C., Bumbaugh A. et al., Parallel evolution of virulence in pathogenic Escherichia coli. Nature. 406: 64-67. 2000. doi: https://doi.org/10.1038/35017546

28. Roberts, J. R. Avian diseases which affect egg production and quality. Inglaterra. Egg chemistry, production and consumption woodhead publishing series in food science, Technology and Nutrition, 376-393. 2011.

29. Russo T, Johnson R. Proposal for a New Inclusive designation for extraintestinal pathogenic isolates of Escherichia coli: expec, The Journal of Infectious Diseases, 181 (5): 1753-1754. 2000. doi: https://doi.org/10.1086/315418

30. Salton M., Shin Kim K. Structure. En: B.s, Medical microbiology. $4^{\text {th }}$ Ed. Glavestone: University of Texas medical branch at galveston. 1996.

31. Touchon M., Hoede C., Tenaillon O., Barbe V., Baeriswyl S., Bidet P., Denamur E. Organised genome dynamics in the Escherichia coli species results in highly diverse adaptive paths. PLoS Genetics, 5 (1): e1000344. 2009. doi: https://doi.org/10.1371/journal.pgen.1000344

32. Vazques C. Escherichia coli patogénica Aviar. ENGOMIX. 2011. Disponible En: https://www.engormix.com/avicultura/articulos/escherichia-coli-patogeno-aviar$\underline{\mathrm{t} 28854 . \mathrm{htm}}$

33. Wirth T., Falush D., Lan R., Colles F., Mensa P., Wieler L., Achtman M. Sex and virulence in Escherichia coli: an evolutionary perspective. Wiley Molecular Microbiology, 1136-1151. 2006.

34.Zhuang Qy Wang, et al., A clinical survey of common avian infectious diseases in China avian dis. Avian Dis, 58 (2): 297-302. 2014.

35. Yassin H., Velthuis G., Boerjan M., Van Riel J. Field study on broilers first week mortality. Poult Sci., 798-804. 2009. 